\title{
METHACHOLINE INDUCED LUNG FUNCTION CHANGES MEASURED WITH INFANT BODY PLETHYSMOGRAPHY
}

\begin{tabular}{|r|l|}
\hline Journal: & Pediatric Pulmonology \\
\hline Manuscript ID: & PPUL-10-0127.R2 \\
\hline Wiley - Manuscript type: & Original Article \\
\hline Date Submitted by the & 03-Sep-2010 \\
\hline Complete List of Authors: & $\begin{array}{l}\text { Malmberg, Leo; Helsinki University Central Hospital, Department of } \\
\text { Allergy } \\
\text { von Wright, Lauri; Helsinki University } \\
\text { Kotaniemi-Syrjänen, Anne; Helsinki University Central Hospital, } \\
\text { Department of Allergology } \\
\text { Malmström, Kristiina; Helsinki University Central Hospital, } \\
\text { Department of Allergology } \\
\text { Pelkonen, Anna; Helsiniki University Central Hospital, Department } \\
\text { of Allergology } \\
\text { Mäkelä, Mika; Helsinki University Hospital, Allergology }\end{array}$ \\
\hline Keywords: & $\begin{array}{l}\text { Bronchial provocation tests, Forced expiratory flow, Body } \\
\text { plethysmography, Infant }\end{array}$ \\
\hline
\end{tabular}


Figure 1. The relationship between methacholine induced post-challenge changes in sGaw and VmaxFRC. The vertical and horizontal lines represent corresponding cutoffs of significant change. $72 \times 59 \mathrm{~mm}(600 \times 600 \mathrm{DPI})$ 
Figure 2. The relationship between dose response slopes (DRS) by sGaw and VmaxFRC during methacholine airway challenge. $73 \times 60 \mathrm{~mm}(600 \times 600 \mathrm{DPI})$

John Wiley \& Sons, Inc. 
Table 1. Demographic data of the study infants.

$\mathrm{N}$

Boys

Age, mo

Gestational age, wk

Length, cm

Weight, $\mathrm{kg}$

Atopy"

Family history of atopy or asthma

Parental smoking

Dominant respiratory symptom

-cough or excess sputum

-wheezy breathing

-dyspnoe or laborious breathing

Physician confirmed wheeze
94

$72(77 \%)$

$14.0(6.0-30.0)^{*}$

$39.7(28.4-42.0)^{*}$

$78.3(63.5-91.5)^{*}$

$10.7(6.5-18.2)^{*}$

$44(47 \%)$

$80(85 \%)$

$31(33 \%)$

$52(55 \%)$

$23(25 \%)$

$19(20 \%)$

$74(79 \%)$

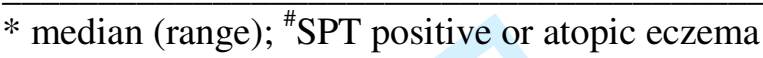


Table 2. Mean (SD) baseline and postchallenge lung function, and change from baseline expressed as absolute units (abs), percentage change (\%) and as multiples of within subject variation (standard deviation) at baseline $\left(\mathrm{SD}_{\mathrm{ws}}\right)$.

Baseline Postchallenge Change (abs) Change (\%) Change ( $\left.\mathrm{SD}_{\mathrm{ws}}\right)$

FRC, $\mathrm{ml}$ $240(55)$

$279(69)^{*}$

$39(36)^{\#}$

Change $(\%)$

sGaw, $\mathrm{kPa}^{-1} \mathrm{~s}^{-1}$

$3.3(2.8) \quad 1.4(1.0)^{*}$

$-1.9(2.4)^{\#}$

$17(17)^{\#}$

$-48(27)^{\#}$

$5.6(7.4)^{\#}$

$\mathrm{V}_{\max } \mathrm{FRC}, \mathrm{ml} / \mathrm{s}$

$237(124) \quad 116(88)^{*}$

$-121(92)^{\#}$

$-51(21)^{\#}$

$-3(2)^{\#}$

$-3(2)^{\#}$

$-5.0(4.1)^{\#}$

$\mathrm{SaO}_{2}, \%$

96 (1)

$93(2)^{*}$

sample t-test

${ }^{*} \mathrm{p}<0.001$ compared to baseline; ${ }^{*} \mathrm{p}<0.001$, one sample t-test 
Table 3. The relationship (correlation coefficients) of postchallenge percentage changes in sGaw, FRC, $\mathrm{SaO}_{2}$ and $\mathrm{V}_{\max }$ FRC.

\begin{tabular}{llll}
\hline & sGaw & FRC & $\mathrm{SaO}_{2}$ \\
\hline $\mathrm{V}_{\max }$ FRC & $0.30(\mathrm{p}=0.004)$ & $-0.27(\mathrm{p}=0.008)$ & $0.33(\mathrm{p}=0.001)$ \\
$\mathrm{SGaw}$ & & $-0.12(\mathrm{p}=0.24)$ & $0.21(\mathrm{p}=0.04)$ \\
$\mathrm{FRC}$ & & & $-0.09(\mathrm{p}=0.41)$ \\
\hline
\end{tabular}




\section{METHACHOLINE INDUCED LUNG FUNCTION CHANGES MEASURED WITH INFANT BODY PLETHYSMOGRAPHY \\ L. Pekka Malmberg, MD, PhD, Lauri von Wright, BM, Anne Kotaniemi-Syrjänen, $\mathrm{MD}, \mathrm{PhD}$, Kristiina Malmström, MD, PhD, Anna S. Pelkonen, MD, PhD, Mika J. Mäkelä, MD, PhD \\ Department of Allergy, Helsinki University Central Hospital, Helsinki, Finland}

Correspondence

Dr. L. Pekka Malmberg, MD, PhD

Department of Allergy, Helsinki University Central Hospital PoBox 160, 00029 HUS

Helsinki, Finland

Tel. +358947186217

Fax. +358947186280

email. pekka.malmberg@hus.fi

Grants: The study was financially supported by Helsinki University Central Hospital Research Fund, Sigrid Juselius Foundation, Foundation for Paediatric Research in Finland, Nummela Sanatorium Foundation, and Finska Läkaresällskapet. An unrestricted research grant was received from Merck Sharp \& Dohme Ltd.

Abbreviated title: AR measured by infant body plethysmography 
SUMMARY

Several techniques have been applied to measure airway responsiveness (AR) in infants, but there are limited data on lung function changes measured by body plethysmography during induced bronchoconstriction. The aim of this study was to compare changes in maximum forced expiratory flow measured at functional residual capacity ( $\mathrm{V}^{\prime}$ maxFRC) by rapid thoracoabdominal compression (RTC) technique with plethysmographic measurements of specific airway conductance $\left(\mathrm{sG}_{\mathrm{aw}}\right)$, and to investigate whether changes in FRC occur during methacholine induced bronchoconstriction in infants.

We examined 94 infants with recurrent airway symptoms using methacholine airway challenge test including RTC and plethysmographic measurements. A significant association between changes in $\mathrm{V}_{\text {maxFRC }}^{\prime}$ and $\mathrm{sG}_{\mathrm{aw}}(\mathrm{r}=0.30 ; \mathrm{p}=0.004)$ was observed, but after adjustments with baseline variability the changes in $\mathrm{V}_{\operatorname{maxFRC}}^{\prime}$ were greater and showed a closer association with changes in oxygen saturation. At the point of maximal airway obstruction, there was a poor agreement between $\mathrm{V}_{\operatorname{maxFRC}}$ and $\mathrm{sG}_{\mathrm{aw}}$ to indicate a significant methacholine induced bronchoconstriction. Airway challenge was also associated with a significant increase in FRC $(\mathrm{p}<0.001)$, with decreasing $\mathrm{V}_{\text {maxFRC. }}$

We conclude that in infants undergoing airway challenge with methacholine, plethysmographic measurements of $\mathrm{sG}_{\mathrm{aw}}$ correlate with the changes in $\mathrm{V}_{\text {maxFRC }}$, but the agreement is poor and the methods cannot be used interchangeably. $\mathrm{V}_{\operatorname{maxFRC}}$ is also more sensitive to detect airway obstruction than $\mathrm{sG}_{\mathrm{aw}}$. However, methacholine induced bronchoconstriction was associated with significant increases in FRC, which may affect the validity of $\mathrm{V}_{\max F \mathrm{C} C}$ measurements during the test.

\section{KEYWORDS}

Bronchial provocation tests, forced expiratory flow, body plethysmography, infants 


\section{INTRODUCTION}

Increased airway responsiveness (AR) is considered one of the basic pathophysiological manifestations of asthma. In infants, the relationship between wheezing lower respiratory tract illnesses and AR is more complex. While associated with clinical features such as atopy, current airway symptoms and the viral aetiology of wheeze, ${ }^{1}$ the predictive value of AR in infancy is still unclear. Two longitudinal studies of randomly ascertained birth cohorts have suggested an association with abnormal airway function, persistence of lower respiratory symptoms and emergence of asthma later in life, ${ }^{2,3}$ but in a four-year prospective study of wheezy children, the level of AR showed no predictive value. ${ }^{4}$ While the contribution of AR measurements in the clinical assessment of infants with recurrent airway symptoms may be questioned, ${ }^{5}$ they afford an important tool for research of the pathophysiology, outcome and interventions of wheezing disorders in infancy.

The measurement of AR in infants requires a method to administer bronchoconstrictive agents (such as methacholine or histamine) and lung function tests to measure response to the test agonist. Rapid thoracoabdominal compression (RTC) is one of the lung function techniques which is standardized ${ }^{6}$ and can be applied in the measurement of AR in infants. It enables the assessment of maximal flow at functional residual capacity $\left(\mathrm{V}_{\text {maxFRC }}^{\prime}\right)$ and requires several squeeze maneuvers to be conducted. During airway challenge tests, however, it is unclear whether repeated forceful compression of the thoracic cage affects infant bronchial tone as such, and whether induced bronchoconstriction may cause changes in the functional residual capacity (FRC) that could affect the validity of serial $\mathrm{V}_{\text {maxFRC }}$ measurements.

Plethysmographic method for measuring FRC and airway resistance $\left(\mathrm{R}_{\mathrm{aw}}\right)$ was introduced in the late 1950s and has been later modified and standardized for use in young children and infants. ${ }^{7}$ Theoretically, plethysmography can be used to monitor infant lung function during bronchial provocation testing by measuring changes in Raw, with the advantage of following simultaneous changes in FRC and conducting measurements during tidal breathing, without forced manouvres. However, so far there have been no attempts to compare lung function measurements by body plethysmography with those of RTC during airway challenge testing in infants. 
The aim of the study was to compare methacholine induced changes in lung function by body plethysmography, with those measured by more conventional RTCtechnique. ${ }^{1}$ Specifically, we aimed to test the agreement between the changes in $\mathrm{V}^{\prime}{ }_{\text {maxFRC }}$ and the change in plethysmographic measurements of specific airway conductance $\left(\mathrm{sG}_{\mathrm{aw}}\right)$, both indexes of airway patency, and additionally to investigate whether changes in FRC occur during methacholine induced bronchoconstriction. Therefore, in a series of 94 infants undergoing airway challenge testing with the RTC technique, baseline and post-challenge measurements with infant body plethysmography were included. 


\section{METHODS}

Study subjects

The study consists of data of 94 infants, who had been referred to a tertiary center (Dept of Allergology, Helsinki University Central Hospital, Helsinki, Finland) due to recurrent airway symptoms and underwent a complete and successful airway challenge test between May 12, 2004 and June 20, 2007. These infants constituted part of the recruitment cohort of a prospective intervention study into infant asthma. The design of the current study was observational, and the number of infants undergoing the challenge test was powered only for the prospective study. The intervention study, including the performance of the baseline lung function and airway challenge tests during the recruitment phase, was approved by the local ethics committee. The tests were conducted after informed consent to conduct these tests had been received from the parents. The parents gave also their consent for the use of the lung function and airway challenge test results for research purposes. The demographic data of the study infants have been shown in Table 1. The mean (SD) duration of the infants' respiratory symptoms (cough, dyspnea or wheeze) was 7.5 (3.8) months, and $79 \%$ of the infants had a history of physician confirmed wheeze. 42 $\%$ had atopic dermatitis, and a family history of asthma or allergy was found in $85 \%$. Five of the infants had born preterm (gestational age $<36$ weeks), and one of them (gestational age 28.4 weeks) needed ventilatory support and continuous oxygen supply for 2 weeks after birth due to respiratory distress syndrome (RDS).

\section{Lung function tests}

Before lung function measurements, the infants were clinically examined to exclude current respiratory infection or clinical obstruction. $\beta_{2}$-agonists were withheld for $12 \mathrm{~h}$ prior to testing. The infants were sedated with orally administered chloralhydrate (50 - $100 \mathrm{mg} / \mathrm{kg}$; maximum dose $1000 \mathrm{mg}$ ). Oxygen saturation (SaO2) and heart rate were continuously monitored during lung function tests and airway challenge with a pulse oximeter (Biox 3700e; Ohmeda, Louisville, KY, USA). 
During lung function testing, the infant was lying supine with the head supported in the midline and the neck slightly extended to minimise airway or glottic obstruction. All measurements were recorded and calculations performed with a commercial paediatric pulmonary function equipment (Babybody Masterscreen, Jaeger GmbH, Würzburg, Germany). The functional residual capacity (FRC) and specific airway conductance $\left(\mathrm{sG}_{\mathrm{aw}}\right)$ were measured by whole body plethysmography employing an electronic algorithm to compensate for differences of temperature and humidity between inspired and expired air. ${ }^{8}$ FRC was measured by selecting artifact free mouth vs. box pressure tracings during endinspiratory occlusion which were not preceded by pressure drift within the box, and did not show signs of leakage (such as change in endexpiratory level after occlusion). Accordingly, pressure-flow tracings were recorded during stable tidal breathing. Airway resistance was measured from the linear portion of the pressure-flow curve between $50 \%$ of the maximum inspiratory and expiratory tidal flow, respectively. Loops without distortion due to artifacts and with minimal thermal drift were chosen. At the baseline, two sets of measurements including 3-5 occlusions and pressure-flow tracings were recorded to calculate the mean $\mathrm{FRC}$ and $\mathrm{sG}_{\mathrm{aw}}$ and their baseline within-subject variation $\left(\mathrm{SD}_{\mathrm{ws}}\right){ }^{9}$

The baseline measurements with body plethysmography were followed by the assessment of partial expiratory flow volume curves. ${ }^{6}$ The maximum flow at FRC ( $\mathrm{V}^{\prime}{ }_{\text {maxFRC}}$ ) was determined using the RTC technique. The jacket was wrapped around the infant's chest and abdomen with the arms extended outside the jacket. Flow was measured at the infant's nose and mouth with a pneumotachometer attached to a face mask. A rim of silicone putty was applied around the mouth and nose and to the face mask to provide an airtight seal. The compression pressure was progressively increased until there was no further increase in $V^{\prime}$ maxFRC. The flow volume curves were considered acceptable when the peak flow occurred prior to expiring $50 \%$ of the tidal volume, there were no transients in the tracings in the region of $\mathrm{FRC}$, and forced expiration lasted long enough to allow recording of flow at FRC. According to our protocol, which is similar to that used in the study of the reference values for $\mathrm{V}^{\prime}{ }_{\text {maxFRC, }}{ }^{10}$ three acceptable maximal partial expiratory flow volume curves were recorded to calculate the mean $\mathrm{V}^{\prime}{ }_{\operatorname{maxFRC}}$ and its baseline within-subject variation $\left(\mathrm{SD}_{\mathrm{ws}}\right)$. 
Methacholine airway challenge

The details of the methacholine airway challenge have been described earlier. ${ }^{1}$ After

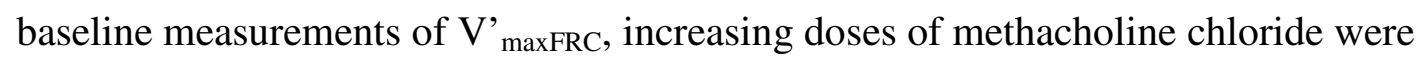
administered by using an inhalation-synchonized dosimeter (Spira Electro 2, Spira Respiratory Care Centre Ltd, Hämeenlinna, Finland). The dosimeter was set to be triggered by an inhaled volume of $20 \mathrm{ml}$, after which a methacholine chloride dose of $50 \mu \mathrm{g}$ was nebulised within 0.2 seconds in an air volume of $25 \mathrm{ml}$, in each breath. The dosimeter incorporates an indicator for inspiratory flows and volumes, which were carefully monitored during the administration of methacholine to ensure sufficient tidal flows (>100 ml/s) and volumes (>50 ml). By calculating the number of breaths with nebulised methacholine, a rapid dosage scheme with four non-cumulative dose steps was applied $(0.1,0.3,0.9$ and $1.8 \mathrm{mg})$, with $\mathrm{V}^{\prime}{ }_{\text {max,FRC }}$ being recorded after each dose (mean of 2-3 acceptable curves). The procedure was continued until a $40 \%$ decrease in $\mathrm{V}$ ' $\operatorname{maxFRC}$ was observed or the maximum dose of methacholine had been administered. At each phase, the applied compression pressure was the same as that which achieved the highest flows at baseline. After the final measurement of

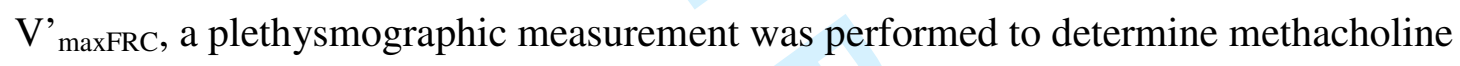
induced changes in FRC and $\mathrm{sG}_{\mathrm{aw}}$. A similar set of measurements were recorded as in the baseline, to assess postchallenge mean FRC and $\mathrm{sG}_{\mathrm{aw}}$. The lowest postchallenge value for $\mathrm{SaO} 2$ was also recorded. Only infants with a complete, uninterrupted methacholine challenge test including successful baseline and post challenge measurements of FRC, $\mathrm{sG}_{\mathrm{aw}}$ and $\mathrm{V}$ ' ${ }_{\text {maxFRC }}$ were included in the study.

The provocative dose of methacholine causing a $40 \%$ fall in $\mathrm{V}^{\prime}{ }_{\operatorname{maxFRC}}\left(\mathrm{PD}_{40} \mathrm{~V}^{\prime}{ }_{\text {macFRC }}\right)$ was determined from the dose-response curves. In addition, the degree of AR was estimated by calculating the dose response slope (DRS), ${ }^{11}$ by dividing the maximum percentage change in lung function with the maximum dose of methacholine administered.

Following the challenge test, the infants received inhaled salbutamol $(0.6 \mathrm{mg}, 0.1$ mg.dose ${ }^{-1}$; Ventoline Evohaler ${ }_{\circledast}$; GlaxoSmithKline, Middlesex, UK) via nebunette ${ }_{\circledast}$ (AstraZeneca, Södertälje, Sweden), and the measurement of V' ${ }^{\text {maxFRC }}$ was repeated 15 min after the salbutamol inhalation. 
Statistics

For statistical analysis, SPSS 17.0 for Windows (SPSS Inc. Chicago, IL, USA) was used. Mean values, within subject standard deviation $\left(\mathrm{SD}_{\mathrm{ws}}\right)$ and coefficient of variation $(\mathrm{CV})$ were calculated for each of the baseline variables. Post-challenge changes in lung function were expressed as absolute units, percentage changes and as multiples of $\mathrm{SD}_{\mathrm{ws}}$-units, the latter indicating the change in absolute units divided by the within subject SD at baseline.

Scatter plots of the change in $\mathrm{FRC}, \mathrm{sG}_{\mathrm{aw}}$ and $\mathrm{SaO}_{2}$ were formed as a function of the change in $\mathrm{V}^{\prime}{ }_{\operatorname{maxFRC}}$ and the corresponding relationships were determined using linear regression analysis. The response data were divided into binomial classes according to the cutoff which was considered as a significant change indicating methacholine induced bronchoconstriction. For V' $\mathrm{maxFRC}$, a decrease of $40 \%$ or more was considered significant. Regression analysis was used to define a corresponding cutoff value for the change in $\mathrm{sG}_{\mathrm{aw}}$ and the data was classified accordingly. Kappa-analysis was applied to assess agreement between these new binomial class variables of $\mathrm{V}^{\prime}{ }_{\text {maxFRC }}$ and $\mathrm{sG}_{\mathrm{aw}}$.

DRSs were calculated for each infant, based on the maximum dose of methacholine, and pre- and postchallenge results of $\mathrm{V}^{\prime}{ }_{\operatorname{maxFRC}}$ and $\mathrm{sG}_{\mathrm{aw}}$. Due to distribution of DRS data, $\log 10$-based transformation was used, and the degree of airway responsiveness thereby assessed by using $\mathrm{V}^{\prime}{ }_{\operatorname{maxFRC}}$ and $\mathrm{sG}_{\mathrm{aw}}$ data, were compared with regression analysis. 


\section{RESULTS}

Table 2 presents a summary of the baseline and post-challenge measurements and the changes in $\mathrm{FRC}, \mathrm{sG}_{\mathrm{aw}}, \mathrm{V}^{\prime}$ maxFRC and $\mathrm{SaO}_{2}$ during methacholine challenge. The median within subject $\mathrm{CVs}$ in baseline $\mathrm{FRC}, \mathrm{V}_{\text {maxFRC }}$ and $\mathrm{sG}_{\mathrm{aw}}$ were 3.3, 4.4 and $10.1 \%$, respectively. As a response to methacholine, sGaw, $\mathrm{V}_{\operatorname{maxFRC}}$ and $\mathrm{SaO}_{2}$ decreased, and FRC increased significantly. The post-challenge percentage changes in sGaw and $\mathrm{V}$ ' ${ }_{\text {maxFRC }}$ were similar, but expressed as multiples of the baseline within-subject variation, $\mathrm{V}^{\prime}{ }_{\operatorname{maxFRC}}$ showed a greater change, indicating better sensitivity to assess methacholine induced bronchoconstriction.

Figure 1 shows the scatter plot between postchallenge changes in $\mathrm{sG}_{\mathrm{aw}}$ and $\mathrm{V}^{\prime}{ }_{\text {maxFRC}}$, indicating a loose assocition. V' ${ }_{\text {maxFRC }}$ showed also an correlation of similar degree with postchallenge changes in airway resistance (Raw) $(r=-0.23 ; p=0.025)$. Almost all of the studied infants responded to methacholine challenge with decreases in both $\mathrm{V}$ ' ${ }_{\text {maxFRC }}$ and $\mathrm{sG}_{\mathrm{aw}}$. The correlation coefficients between postchallenge changes in FRC, $\mathrm{sG}_{\mathrm{aw}}, \mathrm{SaO}_{2}$ and FRC have been presented in Table 3. The changes in $\mathrm{V}^{\prime}$ maxFRC were significantly associated with changes in $\mathrm{FRC}$ and $\mathrm{SaO}_{2}$, but $\mathrm{sG}_{\mathrm{aw}}$ showed a weaker relationship with $\mathrm{SaO}_{2}$ and no correlation to FRC.

Based on regression analysis between $\mathrm{V}^{\prime}{ }_{\operatorname{maxFRC}}$ and $\mathrm{sG}_{\mathrm{aw}}$, a $40 \%$ decrease in $\mathrm{V}^{\prime}{ }_{\operatorname{maxFRC}}$ was approximately comparable to a $35 \%$ decrease in $\mathrm{sG}_{\mathrm{aw}}$. Accordingly the changes in $\mathrm{V}^{\prime}{ }_{\operatorname{maxFRC}}$ and $\mathrm{sG}_{\mathrm{aw}}$ were divided into two classes (significant or non-significant), indicated in Figure 1 as horizontal and vertical lines. Crosstabulation and kappaanalysis of these binomial classes gave the $\kappa$-value of $0.057(\mathrm{p}=0.56)$ indicating poor agreement between the $\mathrm{V}^{\prime}{ }_{\operatorname{maxFRC}}$ and $\mathrm{sG}_{\mathrm{aw}}$ as measures of methacholine induced bronchoconstriction.

In the current study group of infants with recurrent airway symptoms, the median (range) $\mathrm{PD}_{40} \mathrm{~V}_{\operatorname{maxFRC}}^{\prime}$ was $0.54(0.05$ - >1.8) $\mathrm{mg}$ of methacholine. Figure 2 shows a significant association of the estimated AR in terms of the $\log \mathrm{DRS}$ using $\mathrm{Vm}_{\mathrm{axFRC}}$ and $\mathrm{sG}_{\mathrm{aw}}$ data, the value of 0 indicating no response, and higher values increasing responsiveness. 


\section{DISCUSSION}

In infants undergoing airway challenge with methacholine, an expected association between $\mathrm{V}_{\text {maxFRC }}^{\prime}$ and plethysmographic measurements of $\mathrm{sG}_{\mathrm{aw}}$, both indices of airway patency, was observed. However, this relationship was rather weak and there was a poor agreement between these variables to indicate a significant methacholine induced bronchoconstriction. Interestingly, challenging infants with methacholine have also significant effects to their FRC levels, determined by body plethysmography. This may have implications to the validity of $\mathrm{V}_{\operatorname{maxFRC}}$ measurements during the test.

Difficulties in standardizing the bronchial challenge tests in infants have been acknowledged previously. ${ }^{12}$ In particular, the dose of the test agonist is difficult to adjust for children of different size. We have chosen a direct-acting bronchoconstrictor methacholine, which was administered using a rapid dosimetric method found safe and well tolerated by infants. ${ }^{1}$ Furthermore, different lung function methods are available to assess the response to the bronchoconstricting agent. The original approaches to evaluate airway responsiveness to histamine or methacholine in infants applied partial expiratory flow volume curves by using the RTC technique. ${ }^{13-15}$ Subsequently, a methodology using the raised volume forced expiration technique was reported, which enables measurements of forced expiratory volumes as indices of airway patency. ${ }^{16}$ There are a limited number of studies evaluating other lung function techniques to assess histamine or methacholine induced bronchoconstriction, than forced expiration. Benoist et al. ${ }^{17}$ compared the ability of $\mathrm{V}_{\text {maxFRC }}$, tidal breathing parameters and measures of passive respiratory mechanics to assess a response to methacholine determined by a decrease in transcutaneous oxygen tension. They concluded that all these noninvasive lung function tests could be used to detect minor or moderate airway obstruction. Springer et al. ${ }^{18}$ studied thoracoabdominal asynchrony in 17 infants by using respiratory inductance plethysmography during a methacholine challenge, and found the method sensitive enough to measure bronchial reactivity in most $(82 \%)$ of the children. In a large sample of infants, measurements of transcutaneous oxygen tension and forced expiratory volume in 0.5 second by raised volume RTC technique were superior in sensitivity during induced airway obstruction, compared to auscultation or tidal breathing indexes. ${ }^{19}$ By using low 
frequency forced oscillation it has been also shown that inhaled methacholine alters both airway and respiratory tissue mechanics in infants. ${ }^{20}$ Only a few studies have applied infant whole body plethysmography during airway challenge testing. ${ }^{21-23}$ In principle, this method allows rapid assessment of changes in airway resistance with simultaneous measurements of lung volumes (FRC). The potential advantage over forced expirations is that the measurements take place during normal tidal breathing, without interfering the breathing pattern, bronchial tone or resting lung volumes levels. ${ }^{24}$ Although some comparative studies have been published in awake preschool children, ${ }^{25,26}$ so far, there have been no attempts to compare whole body plethysmography and RTC technique in assessing airway responsiveness in sedated infants.

The present results in infants during airway challenge demonstrate that plethysmographic measurements of $\mathrm{sG}_{\mathrm{aw}}$ result in an estimate of airway responsiveness that closely correlates with that based on the response in $\mathrm{V}_{\text {maxFRC. }}^{\prime}$ However, at the point of maximal and similar degree of airway obstruction, there seems to be a poor agreement between the two lung function methods, indicating that their physiological determinants are different. Little is known of the structure/function relationships of infants' airways, but it is assumed that measures of airway resistance reflect mainly changes in the larger airways, and forced expiratory flows at the end expiratory level are more sensitive to peripheral airway obstruction. ${ }^{5}$ As the precise target of the test agonist in the bronchial tree is largely unknown and possibly varies between individual infants, the significance of these physiological mechanisms remain hypothetical. Factors associated with the infant's status (such as posture, changing breathing pattern, sleep state, glottis closure) as well as method-specific sources of error increase the inherent variability and probably also contribute to the disagreement between the two estimates of airway obstruction. ${ }^{6,7}$ In the current settings, the within-subject variation of $\mathrm{V}_{\operatorname{maxFRC}}$ was significantly lower than that of $\mathrm{sG}_{\mathrm{aw}}$. This resulted in a more pronounced postchallenge change in $\mathrm{V}_{\operatorname{maxFRC}}$ than in $\mathrm{sG}_{\mathrm{aw}}$, when expressed as multiples of baseline $\mathrm{SD}_{\mathrm{ws}}$, suggesting that the former is a more sensitive measure of methacholine induced bronchoconstriction. Closer association of $\mathrm{SaO}_{2}$ with $\mathrm{V}_{\text {maxFRC }}$ also favours its use over $\mathrm{sG}_{\mathrm{aw}}$ in the assessment of response during airway challenge. 
In the present study infants, methacholine induced airway obstruction was associated with a significant increase in FRC level, determined by body plethysmography. The prior repeated forced expirations should not significantly alter FRC, ${ }^{27}$ therefore methacholine induced dynamic changes in breathing pattern or air trapping are more likely mechanisms. The finding is important, since the measurements of $\mathrm{V}_{\operatorname{maxFRC}}$ are dependent on the actual end expiratory lung volume, and an increase in FRC may result in an underestimation of the decrease in $\mathrm{V}_{\operatorname{maxFRC}}$ during the challenge test. The observation is also a strong argument to favor raised volume RTC technique in bronchial challenge testing of infants, since forced expiratory volumes after full lung inflation are not effected by changes in FRC level. Dynamic instability of FRC in infants is a major source of variability of $\mathrm{V}_{\text {maxFRC }}$ measurements. ${ }^{28}$ However, in a study of infants comparing tidal and raised volume RTC measurements during methacholine airway challenge, the agreement between the two methods was good and neither showed any obvious advantages over the other. ${ }^{16}$

Changes in lung function were induced by methacholine, which has a limited time of action. The postchallenge measurements of lung function were assessed in a fixed sequence, as the decrease of $\mathrm{V}^{\prime}{ }_{\max F R C}$ was followed as an endpoint criterion of the challenge test. Time dependent alleviation of airway obstruction would thus favour sensitivity of the RTC method over that of sGaw, and affect the association between them as well as with $\mathrm{SaO} 2$. However, studies on the time course of the methacholine induced bronchoconstriction have shown that, even though the peak action usually occurs within 4 minutes, it is followed by a plateau phase where significant bronchoconstriction is sustained for over 15 minutes. ${ }^{29}$ In a similar comparative study of four different lung function methods in preschool children, Klug and Bisgaard ${ }^{25}$ found relatively stable airway obstruction for at least 10 minutes after methacholine inhalation. This time frame was found to be sufficient in the current study to make all the postchallenge measurements ( $\mathrm{V}^{\prime}{ }_{\max }{ }_{\mathrm{FRC}}, \mathrm{FRC}$ and sGaw). Accordingly, they should not be severely affected by time dependent changes of airway obstruction.

We conclude that in infants undergoing airway challenge with methacholine, plethysmographic measurements of $\mathrm{sG}_{\mathrm{aw}}$ correlate with the changes in $\mathrm{V}_{\text {maxFRC}}$, but the agreement is poor and the methods cannot be used interchangeably. $V_{\operatorname{maxFRC}}$ is also more sensitive to detect airway obstruction than $\mathrm{sG}_{\mathrm{aw}}$. However, methacholine 
induced bronchoconstriction was associated with significant increases in FRC, which may affect the validity of $\mathrm{V}_{\operatorname{maxFRC}}$ measurements during the test. 


\section{ACKNOWLEDGEMENTS}

We wish to thank Tuija Rito, RN, and Helena Punkari, RN, for their skill and care with the infants and their parents. The personnel of Spira Respiratory Care Center Ltd, is acknowledged for their help in the development of the inhalation-synchronized dosimetric equipment used in the methacholine challenge.

\section{CONFLICTS OF INTEREST}

None of the authors has any competing interests to declare. 


\section{FIGURE LEGENDS}

Figure 1. The relationship between methacholine induced post-challenge changes in sGaw and VmaxFRC. The vertical and horizontal lines represent corresponding cutoffs of significant change.

Figure 2. The relationship between dose response slopes (DRS) by sGaw and VmaxFRC during methacholine airway challenge. 


\section{REFERENCES}

1. Kotaniemi-Syrjänen A, Malmberg LP, Pelkonen A, Malmström K, Mäkelä M. Airway responsiveness: associated features in infants with recurrent respiratory symptoms. Eur Resp J 2007;30:1150-1157.

2. Palmer LJ, Rye PJ, Gibson NA, Burton PR, Landau LI, Le Souef PN. Airway responsivess in early infancy predicts asthma, lung function and respiratory symptoms by school age. Am J Respir Crit Care Med 2001;163:37-42.

3. Turner SW, Young S, Goldblatt J, Landau LI, Le Souef PN. Childhood asthma and increased airway responsiveness. A relationship that begins in infancy. Am J Respir Crit Care Med 2008;179:98-104.

4. Delacourt C, Benoist MR, Waernessyckle S, Rufin P, Brouard JJ, de Blic J, Scheinmann P. Relationship between bronchial responsiveness and clinical evolution in infants who wheeze. Am J Respir Crit Care Med 2001;164:13821386.

5. Frey U. Clinical applications of infant lung function testing: does it contribute to clinical decision making ? Pediatr Respir Rev 2001;2:126-130.

6. Sly PD, Tepper RS, Henschen M, Gappa M, Stocks J. ERS/ATS Task force on standards for infant respiratory function testing. Tidal forced expirations. Eur Resp J 2000;16:741-748.

7. Stocks J, Godfrey S, Beardsmore C, Bar-Yishay E, Castile E. Plethysmographic measurements of lung volume and airway resistance. Eur Resp J 2001;17:302-312.

8. Reinmann B, Stocks J, Frey U. Assessment of an infant whole-body plethysmograph using an infant lung model. Eur Respir J 2001;17:765-772.

9. Malmberg LP, Pelkonen A, Hakulinen A, Hero M, Pohjavuori M, Skyttä J, Turpeinen M. Intraindividual variability of infant whole body plethysmographic measurements: effects of age and disease. Pediatr Pulmonol 1999;28:356-362.

10. Hoo A-F, Dezateux C, Hanrahan JP, Cole TJ, Tepper R, Stocks J. Sex-specific prediction equations for V'maxFRC in infancy. A multicenter study. Am J Respir Crit Care Med 2002;165:1085-1092. 
11. O'Connor G, Sparrow D, Taylor D, Segal M, Weiss S. Analysis of doseresponse curves to methacholine: an approach suitable for population studies. Am Rev Respir Dis 1987;136:1412-1417.

12. Le Souef PN. Validity of methods used to test airway responsiveness in children. Lancet 1992;339:1282-1284.

13. Prendiville A, Green S, Silverman M. Bronchial responsiveness to histamine in wheezy infants. Thorax 1987;42:92-99.

14. Tepper R. Airway reactivity in infants: a positive response to methacholine and metaprotenol. J Appl Physiol 1987;62:1155-1159.

15. Le Souef PN, Geelhoed GC, Turner DJ, Morgan SEG, Landau LI. Response of normal infants to inhaled histamine. Am Rev Respir Dis 1989;139:62-66.

16. Hayden MJ, Devadason SG, Sly PD, Wildhaber J, Le Souef PN. Methacholine responsiveness using the raised volume forced expiration technique in infants. Am J Respir Crit Care Med 1997;155:1670-1675.

17. Benoist MR, Brouard JJ, Rufin P, Delacourt C, Waernessyckle S, Scheinmann P. Ability of new lung function tests to assess methacholine-induced airway obstruction in infants. Pediatr Pulmonol 1994;18:308-316.

18. Springer C, Godfrey S, Vilozni D, Bar-Yishay E, Noviski N, Avital A. Comparison of respiratory inductance plethysmography with thoracoabdominal compression in bronchial challenges in infants and young children. Am J Respir Crit Care Med 1996;154:665-669.

19. Loland L, Buchvald F, Brydensholt Halkjaer L, Anhoj J, Hall G, Persson T, Krause TG, Bisgaard H. Sensitivity of bronchial responsiveness measurements in young infants. Chest 2006;129:669-675.

20. Hall G, Hantos Z, Wildhaber J, F P, Sly PD. Methacholine responsiveness in infants assessed with low frequency forced oscillation and forced expiration techniques. Thorax 2001;56:42-47.

21. Gutkowski P. Airway responsiveness following wheezy bronchitis in infants. Eur Resp J 1990;3:807-811.

22. O'Callaghan C, Milner AD, Webb MS, Swarbrick A. Nebulized water as a bronchoconstricting agent in infancy. Arch Dis Child 1991;66:948-951.

23. Yuksel B, Greenough A. Nebulized sodium cromoglycate in preterm infants protection against water challenge-induced bronchoconstriction. Respir Med 1993;87:37-42. 
24. Lum S, Hulskamp G, Hoo A-F, Ljungberg H, Stocks J. Effect of raised lung volume technique on subsequent measures of VmaxFRC in infants. Pediatr Pulmonol 2004;38:146-154.

25. Klug B, Bisgaard H. Measurement of lung function in awake 2-4-year old asthmatic children during methacholine challenge and acute asthma. Pediatr Pulmonol 1996;21:290-300.

26. Klug B, Bisgaard H. Measurement of the specific airway resistance by plethysmography in young children accompanied by an adult. Eur Respir J 1997;10:1599-1605.

27. Lanteri CJ, Raven JM, Sly PD. Effect of expiration on thoracic gas volume in wheezy infants. Pediatr Pulmonol 1990;9:220-223.

28. Delacourt C, Benoist MR, Waernessyckle S, Rufin P, Brouard JJ, de Blic J, Scheinmann P. Repeatability of lung function tests during methacholine challnge in wheezy infants. Thorax 1998;53:933-938.

29. Cartier A, Malo J-C, Begin P, Sestier M, Martin RR. Time course of the bronchoconstriction induced by inhaled histamine and methacholine. J Appl Physiol 1983;54:821-826. 


\section{METHACHOLINE INDUCED LUNG FUNCTION CHANGES MEASURED WITH INFANT BODY PLETHYSMOGRAPHY \\ L. Pekka Malmberg, MD, PhD, Lauri von Wright, BM, Anne Kotaniemi-Syrjänen, $\mathrm{MD}, \mathrm{PhD}$, Kristiina Malmström, MD, PhD, Anna S. Pelkonen, MD, PhD, Mika J. Mäkelä, MD, PhD \\ Department of Allergy, Helsinki University Central Hospital, Helsinki, Finland}

Correspondence

Dr. L. Pekka Malmberg, MD, PhD

Department of Allergy, Helsinki University Central Hospital PoBox 160, 00029 HUS

Helsinki, Finland

Tel. +358947186217

Fax. +358947186280

email. pekka.malmberg@hus.fi

Grants: The study was financially supported by Helsinki University Central Hospital Research Fund, Sigrid Juselius Foundation, Foundation for Paediatric Research in Finland, Nummela Sanatorium Foundation, and Finska Läkaresällskapet. An unrestricted research grant was received from Merck Sharp \& Dohme Ltd.

Abbreviated title: AR measured by infant body plethysmography 
SUMMARY

Several techniques have been applied to measure airway responsiveness (AR) in infants, but there are limited data on lung function changes measured by body plethysmography during induced bronchoconstriction. The aim of this study was to compare changes in maximum forced expiratory flow measured at functional residual capacity ( $\mathrm{V}^{\prime}$ maxFRC) by rapid thoracoabdominal compression (RTC) technique with plethysmographic measurements of specific airway conductance $\left(\mathrm{sG}_{\mathrm{aw}}\right)$, and to investigate whether changes in FRC occur during methacholine induced bronchoconstriction in infants.

We examined 94 infants with recurrent airway symptoms using methacholine airway challenge test including RTC and plethysmographic measurements. A significant association between changes in $\mathrm{V}_{\text {maxFRC }}^{\prime}$ and $\mathrm{sG}_{\mathrm{aw}}(\mathrm{r}=0.30 ; \mathrm{p}=0.004)$ was observed, but after adjustments with baseline variability the changes in $\mathrm{V}_{\text {maxFRC }}^{\prime}$ were greater and showed a closer association with changes in oxygen saturation. At the point of maximal airway obstruction, there was a poor agreement between $V^{\prime}{ }_{\operatorname{maxFRC}}$ and $\mathrm{sG}_{\mathrm{aw}}$ to indicate a significant methacholine induced bronchoconstriction. Airway challenge was also associated with a significant increase in FRC $(\mathrm{p}<0.001)$, with decreasing $\mathrm{V}_{\text {maxFRC. }}$

We conclude that in infants undergoing airway challenge with methacholine, plethysmographic measurements of $\mathrm{sG}_{\mathrm{aw}}$ correlate with the changes in $\mathrm{V}_{\text {maxFRC }}$, but the agreement is poor and the methods cannot be used interchangeably. $\mathrm{V}_{\operatorname{maxFRC}}$ is also more sensitive to detect airway obstruction than $\mathrm{sG}_{\mathrm{aw}}$. However, methacholine induced bronchoconstriction was associated with significant increases in FRC, which may affect the validity of $\mathrm{V}_{\max F \mathrm{C} C}$ measurements during the test.

\section{KEYWORDS}

Bronchial provocation tests, forced expiratory flow, body plethysmography, infants 


\section{INTRODUCTION}

Increased airway responsiveness (AR) is considered one of the basic pathophysiological manifestations of asthma. In infants, the relationship between wheezing lower respiratory tract illnesses and AR is more complex. While associated with clinical features such as atopy, current airway symptoms and the viral aetiology of wheeze, ${ }^{1}$ the predictive value of AR in infancy is still unclear. Two longitudinal studies of randomly ascertained birth cohorts have suggested an association with abnormal airway function, persistence of lower respiratory symptoms and emergence of asthma later in life, ${ }^{2,3}$ but in a four-year prospective study of wheezy children, the level of AR showed no predictive value. ${ }^{4}$ While the contribution of AR measurements in the clinical assessment of infants with recurrent airway symptoms may be questioned, ${ }^{5}$ they afford an important tool for research of the pathophysiology, outcome and interventions of wheezing disorders in infancy.

The measurement of AR in infants requires a method to administer bronchoconstrictive agents (such as methacholine or histamine) and lung function tests to measure response to the test agonist. Rapid thoracoabdominal compression (RTC) is one of the lung function techniques which is standardized ${ }^{6}$ and can be applied in the measurement of AR in infants. It enables the assessment of maximal flow at functional residual capacity $\left(\mathrm{V}_{\text {maxFRC }}^{\prime}\right)$ and requires several squeeze maneuvers to be conducted. During airway challenge tests, however, it is unclear whether repeated forceful compression of the thoracic cage affects infant bronchial tone as such, and whether induced bronchoconstriction may cause changes in the functional residual capacity (FRC) that could affect the validity of serial $\mathrm{V}_{\text {maxFRC }}$ measurements.

Plethysmographic method for measuring FRC and airway resistance $\left(\mathrm{R}_{\mathrm{aw}}\right)$ was introduced in the late 1950s and has been later modified and standardized for use in young children and infants. ${ }^{7}$ Theoretically, plethysmography can be used to monitor infant lung function during bronchial provocation testing by measuring changes in Raw, with the advantage of following simultaneous changes in FRC and conducting measurements during tidal breathing, without forced manouvres. However, so far there have been no attempts to compare lung function measurements by body plethysmography with those of RTC during airway challenge testing in infants. 
The aim of the study was to compare methacholine induced changes in lung function by body plethysmography, with those measured by more conventional RTCtechnique. ${ }^{1}$ Specifically, we aimed to test the agreement between the changes in $\mathrm{V}^{\prime}{ }_{\text {maxFRC }}$ and the change in plethysmographic measurements of specific airway conductance $\left(\mathrm{sG}_{\mathrm{aw}}\right)$, both indexes of airway patency, and additionally to investigate whether changes in FRC occur during methacholine induced bronchoconstriction. Therefore, in a series of 94 infants undergoing airway challenge testing with the RTC technique, baseline and post-challenge measurements with infant body plethysmography were included. 


\section{METHODS}

Study subjects

The study consists of data of 94 infants, who had been referred to a tertiary center (Dept of Allergology, Helsinki University Central Hospital, Helsinki, Finland) due to recurrent airway symptoms and underwent a complete and successful airway challenge test between May 12, 2004 and June 20, 2007. These infants constituted part of the recruitment cohort of a prospective intervention study into infant asthma. The design of the current study was observational, and the number of infants undergoing the challenge test was powered only for the prospective study. The intervention study, including the performance of the baseline lung function and airway challenge tests during the recruitment phase, was approved by the local ethics committee. The tests were conducted after informed consent to conduct these tests had been received from the parents. The parents gave also their consent for the use of the lung function and airway challenge test results for research purposes. The demographic data of the study infants have been shown in Table 1. The mean (SD) duration of the infants' respiratory symptoms (cough, dyspnea or wheeze) was 7.5 (3.8) months, and $79 \%$ of the infants had a history of physician confirmed wheeze. 42 $\%$ had atopic dermatitis, and a family history of asthma or allergy was found in $85 \%$. Five of the infants had born preterm (gestational age $<36$ weeks), and one of them (gestational age 28.4 weeks) needed ventilatory support and continuous oxygen supply for 2 weeks after birth due to respiratory distress syndrome (RDS).

\section{Lung function tests}

Before lung function measurements, the infants were clinically examined to exclude current respiratory infection or clinical obstruction. $\beta_{2}$-agonists were withheld for $12 \mathrm{~h}$ prior to testing. The infants were sedated with orally administered chloralhydrate (50 - $100 \mathrm{mg} / \mathrm{kg}$; maximum dose $1000 \mathrm{mg}$ ). Oxygen saturation (SaO2) and heart rate were continuously monitored during lung function tests and airway challenge with a pulse oximeter (Biox 3700e; Ohmeda, Louisville, KY, USA). 
During lung function testing, the infant was lying supine with the head supported in the midline and the neck slightly extended to minimise airway or glottic obstruction. All measurements were recorded and calculations performed with a commercial paediatric pulmonary function equipment (Babybody Masterscreen, Jaeger GmbH, Würzburg, Germany). The functional residual capacity (FRC) and specific airway conductance $\left(\mathrm{sG}_{\mathrm{aw}}\right)$ were measured by whole body plethysmography employing an electronic algorithm to compensate for differences of temperature and humidity between inspired and expired air. ${ }^{8}$ FRC was measured by selecting artifact free mouth vs. box pressure tracings during endinspiratory occlusion which were not preceded by pressure drift within the box, and did not show signs of leakage (such as change in endexpiratory level after occlusion). Accordingly, pressure-flow tracings were recorded during stable tidal breathing. Airway resistance was measured from the linear portion of the pressure-flow curve between $50 \%$ of the maximum inspiratory and expiratory tidal flow, respectively. Loops without distortion due to artifacts and with minimal thermal drift were chosen. At the baseline, two sets of measurements including 3-5 occlusions and pressure-flow tracings were recorded to calculate the mean $\mathrm{FRC}$ and $\mathrm{sG}_{\mathrm{aw}}$ and their baseline within-subject variation $\left(\mathrm{SD}_{\mathrm{ws}}\right){ }^{9}$

The baseline measurements with body plethysmography were followed by the assessment of partial expiratory flow volume curves. ${ }^{6}$ The maximum flow at FRC ( $\mathrm{V}^{\prime}{ }_{\text {maxFRC}}$ ) was determined using the RTC technique. The jacket was wrapped around the infant's chest and abdomen with the arms extended outside the jacket. Flow was measured at the infant's nose and mouth with a pneumotachometer attached to a face mask. A rim of silicone putty was applied around the mouth and nose and to the face mask to provide an airtight seal. The compression pressure was progressively

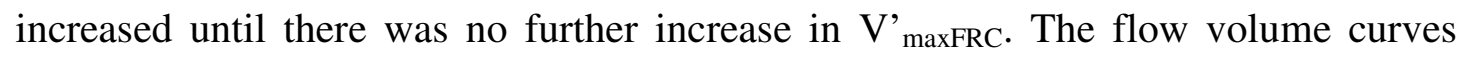
were considered acceptable when the peak flow occurred prior to expiring $50 \%$ of the tidal volume, there were no transients in the tracings in the region of $\mathrm{FRC}$, and forced expiration lasted long enough to allow recording of flow at FRC. According to our protocol, which is similar to that used in the study of the reference values for $\mathrm{V}^{\prime}{ }_{\text {maxFRC}}{ }^{10}$ three acceptable maximal partial expiratory flow volume curves were recorded to calculate the mean $\mathrm{V}^{\prime}{ }_{\operatorname{maxFRC}}$ and its baseline within-subject variation $\left(\mathrm{SD}_{\mathrm{ws}}\right)$. 
Methacholine airway challenge

The details of the methacholine airway challenge have been described earlier. ${ }^{1}$ After

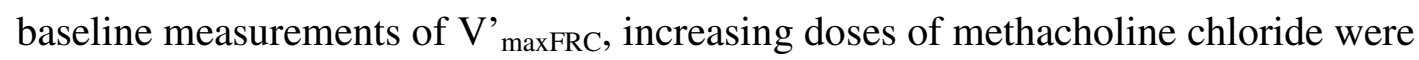
administered by using an inhalation-synchonized dosimeter (Spira Electro 2, Spira Respiratory Care Centre Ltd, Hämeenlinna, Finland). The dosimeter was set to be triggered by an inhaled volume of $20 \mathrm{ml}$, after which a methacholine chloride dose of $50 \mu \mathrm{g}$ was nebulised within 0.2 seconds in an air volume of $25 \mathrm{ml}$, in each breath. The dosimeter incorporates an indicator for inspiratory flows and volumes, which were carefully monitored during the administration of methacholine to ensure sufficient tidal flows (>100 ml/s) and volumes (>50 ml). By calculating the number of breaths with nebulised methacholine, a rapid dosage scheme with four non-cumulative dose steps was applied $(0.1,0.3,0.9$ and $1.8 \mathrm{mg})$, with $\mathrm{V}^{\prime}$ max,FRC being recorded after each dose (mean of 2-3 acceptable curves). The procedure was continued until a $40 \%$ decrease in $\mathrm{V}$ ' $\operatorname{maxFRC}$ was observed or the maximum dose of methacholine had been administered. At each phase, the applied compression pressure was the same as that which achieved the highest flows at baseline. After the final measurement of $\mathrm{V}^{\prime}{ }_{\text {maxFRC}}$, a plethysmographic measurement was performed to determine methacholine induced changes in FRC and $\mathrm{sG}_{\mathrm{aw}}$. A similar set of measurements were recorded as in the baseline, to assess postchallenge mean FRC and $\mathrm{sG}_{\mathrm{aw}}$. The lowest postchallenge value for $\mathrm{SaO} 2$ was also recorded. Only infants with a complete, uninterrupted methacholine challenge test including successful baseline and post challenge measurements of FRC, $\mathrm{sG}_{\mathrm{aw}}$ and $\mathrm{V}$ ' ${ }_{\text {maxFRC }}$ were included in the study.

The provocative dose of methacholine causing a $40 \%$ fall in $\mathrm{V}^{\prime}{ }_{\operatorname{maxFRC}}\left(\mathrm{PD}_{40} \mathrm{~V}^{\prime}{ }_{\text {macFRC }}\right)$ was determined from the dose-response curves. In addition, the degree of AR was estimated by calculating the dose response slope (DRS), ${ }^{11}$ by dividing the maximum percentage change in lung function with the maximum dose of methacholine administered.

Following the challenge test, the infants received inhaled salbutamol $(0.6 \mathrm{mg}, 0.1$ mg.dose ${ }^{-1}$; Ventoline Evohaler ${ }_{\circledast}$; GlaxoSmithKline, Middlesex, UK) via nebunette ${ }_{\circledast}$ (AstraZeneca, Södertälje, Sweden), and the measurement of V' ${ }^{\text {maxFRC }}$ was repeated 15 min after the salbutamol inhalation. 
Statistics

For statistical analysis, SPSS 17.0 for Windows (SPSS Inc. Chicago, IL, USA) was used. Mean values, within subject standard deviation $\left(\mathrm{SD}_{\mathrm{ws}}\right)$ and coefficient of variation $(\mathrm{CV})$ were calculated for each of the baseline variables. Post-challenge changes in lung function were expressed as absolute units, percentage changes and as multiples of $\mathrm{SD}_{\mathrm{ws}}$-units, the latter indicating the change in absolute units divided by the within subject SD at baseline.

Scatter plots of the change in $\mathrm{FRC}, \mathrm{sG}_{\mathrm{aw}}$ and $\mathrm{SaO}_{2}$ were formed as a function of the change in $\mathrm{V}^{\prime}{ }_{\operatorname{maxFRC}}$ and the corresponding relationships were determined using linear regression analysis. The response data were divided into binomial classes according to the cutoff which was considered as a significant change indicating methacholine induced bronchoconstriction. For V' $\mathrm{maxFRC}$, a decrease of $40 \%$ or more was considered significant. Regression analysis was used to define a corresponding cutoff value for the change in $\mathrm{sG}_{\mathrm{aw}}$ and the data was classified accordingly. Kappa-analysis was applied to assess agreement between these new binomial class variables of $\mathrm{V}^{\prime}{ }_{\operatorname{maxFRC}}$ and $\mathrm{sG}_{\mathrm{aw}}$.

DRSs were calculated for each infant, based on the maximum dose of methacholine, and pre- and postchallenge results of $\mathrm{V}^{\prime}{ }_{\operatorname{maxFRC}}$ and $\mathrm{sG}_{\mathrm{aw}}$. Due to distribution of DRS data, $\log 10$-based transformation was used, and the degree of airway responsiveness thereby assessed by using $\mathrm{V}^{\prime}{ }_{\operatorname{maxFRC}}$ and $\mathrm{sG}_{\mathrm{aw}}$ data, were compared with regression analysis. 


\section{RESULTS}

Table 2 presents a summary of the baseline and post-challenge measurements and the changes in $\mathrm{FRC}, \mathrm{sG}_{\mathrm{aw}}, \mathrm{V}^{\prime}$ maxFRC and $\mathrm{SaO}_{2}$ during methacholine challenge. The median within subject $\mathrm{CVs}$ in baseline $\mathrm{FRC}, \mathrm{V}_{\text {maxFRC }}$ and $\mathrm{sG}_{\mathrm{aw}}$ were 3.3, 4.4 and $10.1 \%$, respectively. As a response to methacholine, sGaw, $\mathrm{V}_{\operatorname{maxFRC}}$ and $\mathrm{SaO}_{2}$ decreased, and FRC increased significantly. The post-challenge percentage changes in sGaw and $\mathrm{V}$ ' ${ }_{\text {maxFRC }}$ were similar, but expressed as multiples of the baseline within-subject variation, $\mathrm{V}^{\prime}{ }_{\operatorname{maxFRC}}$ showed a greater change, indicating better sensitivity to assess methacholine induced bronchoconstriction.

Figure 1 shows the scatter plot between postchallenge changes in $\mathrm{sG}_{\mathrm{aw}}$ and $\mathrm{V}^{\prime}{ }_{\text {maxFRC}}$, indicating a loose assocition. V' ${ }_{\text {maxFRC }}$ showed also an correlation of similar degree with postchallenge changes in airway resistance (Raw) $(r=-0.23 ; p=0.025)$. Almost all of the studied infants responded to methacholine challenge with decreases in both $\mathrm{V}$ ' ${ }_{\text {maxFRC }}$ and $\mathrm{sG}_{\mathrm{aw}}$. The correlation coefficients between postchallenge changes in FRC, $\mathrm{sG}_{\mathrm{aw}}, \mathrm{SaO}_{2}$ and FRC have been presented in Table 3. The changes in $\mathrm{V}^{\prime}{ }_{\operatorname{maxFRC}}$ were significantly associated with changes in $\mathrm{FRC}$ and $\mathrm{SaO}_{2}$, but $\mathrm{sG}_{\mathrm{aw}}$ showed a weaker relationship with $\mathrm{SaO}_{2}$ and no correlation to FRC.

Based on regression analysis between $\mathrm{V}^{\prime}{ }_{\operatorname{maxFRC}}$ and $\mathrm{sG}_{\mathrm{aw}}$, a $40 \%$ decrease in $\mathrm{V}^{\prime}{ }_{\operatorname{maxFRC}}$ was approximately comparable to a $35 \%$ decrease in $\mathrm{sG}_{\mathrm{aw}}$. Accordingly the changes in $\mathrm{V}^{\prime}{ }_{\operatorname{maxFRC}}$ and $\mathrm{sG}_{\mathrm{aw}}$ were divided into two classes (significant or non-significant), indicated in Figure 1 as horizontal and vertical lines. Crosstabulation and kappaanalysis of these binomial classes gave the $\kappa$-value of $0.057(\mathrm{p}=0.56)$ indicating poor agreement between the $\mathrm{V}^{\prime}{ }_{\operatorname{maxFRC}}$ and $\mathrm{sG}_{\mathrm{aw}}$ as measures of methacholine induced bronchoconstriction.

In the current study group of infants with recurrent airway symptoms, the median (range) $\mathrm{PD}_{40} \mathrm{~V}_{\operatorname{maxFRC}}^{\prime}$ was $0.54(0.05$ - >1.8) $\mathrm{mg}$ of methacholine. Figure 2 shows a significant association of the estimated AR in terms of the $\log \mathrm{DRS}$ using $\mathrm{Vm}_{\mathrm{axFRC}}$ and $\mathrm{sG}_{\mathrm{aw}}$ data, the value of 0 indicating no response, and higher values increasing responsiveness. 


\section{DISCUSSION}

In infants undergoing airway challenge with methacholine, an expected association between $\mathrm{V}_{\text {maxFRC }}^{\prime}$ and plethysmographic measurements of $\mathrm{sG}_{\mathrm{aw}}$, both indices of airway patency, was observed. However, this relationship was rather weak and there was a poor agreement between these variables to indicate a significant methacholine induced bronchoconstriction. Interestingly, challenging infants with methacholine have also significant effects to their FRC levels, determined by body plethysmography. This may have implications to the validity of $\mathrm{V}_{\operatorname{maxFRC}}$ measurements during the test.

Difficulties in standardizing the bronchial challenge tests in infants have been acknowledged previously. ${ }^{12}$ In particular, the dose of the test agonist is difficult to adjust for children of different size. We have chosen a direct-acting bronchoconstrictor methacholine, which was administered using a rapid dosimetric method found safe and well tolerated by infants. ${ }^{1}$ Furthermore, different lung function methods are available to assess the response to the bronchoconstricting agent. The original approaches to evaluate airway responsiveness to histamine or methacholine in infants applied partial expiratory flow volume curves by using the RTC technique. ${ }^{13-15}$ Subsequently, a methodology using the raised volume forced expiration technique was reported, which enables measurements of forced expiratory volumes as indices of airway patency. ${ }^{16}$ There are a limited number of studies evaluating other lung function techniques to assess histamine or methacholine induced bronchoconstriction, than forced expiration. Benoist et al. ${ }^{17}$ compared the ability of $\mathrm{V}_{\text {maxFRC }}$, tidal breathing parameters and measures of passive respiratory mechanics to assess a response to methacholine determined by a decrease in transcutaneous oxygen tension. They concluded that all these noninvasive lung function tests could be used to detect minor or moderate airway obstruction. Springer et al. ${ }^{18}$ studied thoracoabdominal asynchrony in 17 infants by using respiratory inductance plethysmography during a methacholine challenge, and found the method sensitive enough to measure bronchial reactivity in most $(82 \%)$ of the children. In a large sample of infants, measurements of transcutaneous oxygen tension and forced expiratory volume in 0.5 second by raised volume RTC technique were superior in sensitivity during induced airway obstruction, compared to auscultation or tidal breathing indexes. ${ }^{19}$ By using low 
frequency forced oscillation it has been also shown that inhaled methacholine alters both airway and respiratory tissue mechanics in infants. ${ }^{20}$ Only a few studies have applied infant whole body plethysmography during airway challenge testing. ${ }^{21-23} \mathrm{In}$ principle, this method allows rapid assessment of changes in airway resistance with simultaneous measurements of lung volumes (FRC). The potential advantage over forced expirations is that the measurements take place during normal tidal breathing, without interfering the breathing pattern, bronchial tone or resting lung volumes levels. ${ }^{24}$ Although some comparative studies have been published in awake preschool children, ${ }^{25,26}$ so far, there have been no attempts to compare whole body plethysmography and RTC technique in assessing airway responsiveness in sedated infants.

The present results in infants during airway challenge demonstrate that plethysmographic measurements of $\mathrm{sG}_{\mathrm{aw}}$ result in an estimate of airway responsiveness that closely correlates with that based on the response in $\mathrm{V}_{\text {maxFRC. }}^{\prime}$ However, at the point of maximal and similar degree of airway obstruction, there seems to be a poor agreement between the two lung function methods, indicating that their physiological determinants are different. Little is known of the structure/function relationships of infants' airways, but it is assumed that measures of airway resistance reflect mainly changes in the larger airways, and forced expiratory flows at the end expiratory level are more sensitive to peripheral airway obstruction. ${ }^{5}$ As the precise target of the test agonist in the bronchial tree is largely unknown and possibly varies between individual infants, the significance of these physiological mechanisms remain hypothetical. Factors associated with the infant's status (such as posture, changing breathing pattern, sleep state, glottis closure) as well as method-specific sources of error increase the inherent variability and probably also contribute to the disagreement between the two estimates of airway obstruction. ${ }^{6,7}$ In the current settings, the within-subject variation of $\mathrm{V}_{\operatorname{maxFRC}}$ was significantly lower than that of $\mathrm{sG}_{\mathrm{aw}}$. This resulted in a more pronounced postchallenge change in $\mathrm{V}_{\operatorname{maxFRC}}$ than in $\mathrm{sG}_{\mathrm{aw}}$, when expressed as multiples of baseline $\mathrm{SD}_{\mathrm{ws}}$, suggesting that the former is a more sensitive measure of methacholine induced bronchoconstriction. Closer association of $\mathrm{SaO}_{2}$ with $\mathrm{V}_{\text {maxFRC }}$ also favours its use over $\mathrm{sG}_{\mathrm{aw}}$ in the assessment of response during airway challenge. 
In the present study infants, methacholine induced airway obstruction was associated with a significant increase in FRC level, determined by body plethysmography. The prior repeated forced expirations should not significantly alter FRC, ${ }^{27}$ therefore methacholine induced dynamic changes in breathing pattern or air trapping are more likely mechanisms. The finding is important, since the measurements of $\mathrm{V}_{\operatorname{maxFRC}}$ are dependent on the actual end expiratory lung volume, and an increase in FRC may result in an underestimation of the decrease in $\mathrm{V}_{\operatorname{maxFRC}}$ during the challenge test. The observation is also a strong argument to favor raised volume RTC technique in bronchial challenge testing of infants, since forced expiratory volumes after full lung inflation are not effected by changes in FRC level. Dynamic instability of FRC in infants is a major source of variability of $\mathrm{V}_{\text {maxFRC }}$ measurements. ${ }^{28}$ However, in a study of infants comparing tidal and raised volume RTC measurements during methacholine airway challenge, the agreement between the two methods was good and neither showed any obvious advantages over the other. ${ }^{16}$

Changes in lung function were induced by methacholine, which has a limited time of action. The postchallenge measurements of lung function were assessed in a fixed sequence, as the decrease of $\mathrm{V}^{\prime}{ }_{\max F R C}$ was followed as an endpoint criterion of the challenge test. Time dependent alleviation of airway obstruction would thus favour sensitivity of the RTC method over that of sGaw, and affect the association between them as well as with $\mathrm{SaO} 2$. However, studies on the time course of the methacholine induced bronchoconstriction have shown that, even though the peak action usually occurs within 4 minutes, it is followed by a plateau phase where significant bronchoconstriction is sustained for over 15 minutes. ${ }^{29}$ In a similar comparative study of four different lung function methods in preschool children, Klug and Bisgaard ${ }^{25}$ found relatively stable airway obstruction for at least 10 minutes after methacholine inhalation. This time frame was found to be sufficient in the current study to make all the postchallenge measurements ( $\mathrm{V}^{\prime}$ maxFRC, FRC and sGaw). Accordingly, they should not be severely affected by time dependent changes of airway obstruction.

We conclude that in infants undergoing airway challenge with methacholine, plethysmographic measurements of $\mathrm{sG}_{\mathrm{aw}}$ correlate with the changes in $\mathrm{V}_{\text {maxFRC}}$, but the agreement is poor and the methods cannot be used interchangeably. $V_{\operatorname{maxFRC}}$ is also more sensitive to detect airway obstruction than $\mathrm{sG}_{\mathrm{aw}}$. However, methacholine 
induced bronchoconstriction was associated with significant increases in FRC, which may affect the validity of $\mathrm{V}_{\operatorname{maxFRC}}$ measurements during the test. 


\section{ACKNOWLEDGEMENTS}

We wish to thank Tuija Rito, RN, and Helena Punkari, RN, for their skill and care with the infants and their parents. The personnel of Spira Respiratory Care Center Ltd, is acknowledged for their help in the development of the inhalation-synchronized dosimetric equipment used in the methacholine challenge.

\section{CONFLICTS OF INTEREST}

None of the authors has any competing interests to declare. 


\section{FIGURE LEGENDS}

Figure 1. The relationship between methacholine induced post-challenge changes in sGaw and VmaxFRC. The vertical and horizontal lines represent corresponding cutoffs of significant change.

Figure 2. The relationship between dose response slopes (DRS) by sGaw and VmaxFRC during methacholine airway challenge. 


\section{REFERENCES}

1. Kotaniemi-Syrjänen A, Malmberg LP, Pelkonen A, Malmström K, Mäkelä M. Airway responsiveness: associated features in infants with recurrent respiratory symptoms. Eur Resp J 2007;30:1150-1157.

2. Palmer LJ, Rye PJ, Gibson NA, Burton PR, Landau LI, Le Souef PN. Airway responsivess in early infancy predicts asthma, lung function and respiratory symptoms by school age. Am J Respir Crit Care Med 2001;163:37-42.

3. Turner SW, Young S, Goldblatt J, Landau LI, Le Souef PN. Childhood asthma and increased airway responsiveness. A relationship that begins in infancy. Am J Respir Crit Care Med 2008;179:98-104.

4. Delacourt C, Benoist MR, Waernessyckle S, Rufin P, Brouard JJ, de Blic J, Scheinmann P. Relationship between bronchial responsiveness and clinical evolution in infants who wheeze. Am J Respir Crit Care Med 2001;164:13821386.

5. Frey U. Clinical applications of infant lung function testing: does it contribute to clinical decision making ? Pediatr Respir Rev 2001;2:126-130.

6. Sly PD, Tepper RS, Henschen M, Gappa M, Stocks J. ERS/ATS Task force on standards for infant respiratory function testing. Tidal forced expirations. Eur Resp J 2000;16:741-748.

7. Stocks J, Godfrey S, Beardsmore C, Bar-Yishay E, Castile E. Plethysmographic measurements of lung volume and airway resistance. Eur Resp J 2001;17:302-312.

8. Reinmann B, Stocks J, Frey U. Assessment of an infant whole-body plethysmograph using an infant lung model. Eur Respir J 2001;17:765-772.

9. Malmberg LP, Pelkonen A, Hakulinen A, Hero M, Pohjavuori M, Skyttä J, Turpeinen M. Intraindividual variability of infant whole body plethysmographic measurements: effects of age and disease. Pediatr Pulmonol 1999;28:356-362.

10. Hoo A-F, Dezateux C, Hanrahan JP, Cole TJ, Tepper R, Stocks J. Sex-specific prediction equations for V'maxFRC in infancy. A multicenter study. Am J Respir Crit Care Med 2002;165:1085-1092. 
11. O'Connor G, Sparrow D, Taylor D, Segal M, Weiss S. Analysis of doseresponse curves to methacholine: an approach suitable for population studies. Am Rev Respir Dis 1987;136:1412-1417.

12. Le Souef PN. Validity of methods used to test airway responsiveness in children. Lancet 1992;339:1282-1284.

13. Prendiville A, Green S, Silverman M. Bronchial responsiveness to histamine in wheezy infants. Thorax 1987;42:92-99.

14. Tepper R. Airway reactivity in infants: a positive response to methacholine and metaprotenol. J Appl Physiol 1987;62:1155-1159.

15. Le Souef PN, Geelhoed GC, Turner DJ, Morgan SEG, Landau LI. Response of normal infants to inhaled histamine. Am Rev Respir Dis 1989;139:62-66.

16. Hayden MJ, Devadason SG, Sly PD, Wildhaber J, Le Souef PN. Methacholine responsiveness using the raised volume forced expiration technique in infants. Am J Respir Crit Care Med 1997;155:1670-1675.

17. Benoist MR, Brouard JJ, Rufin P, Delacourt C, Waernessyckle S, Scheinmann P. Ability of new lung function tests to assess methacholine-induced airway obstruction in infants. Pediatr Pulmonol 1994;18:308-316.

18. Springer C, Godfrey S, Vilozni D, Bar-Yishay E, Noviski N, Avital A. Comparison of respiratory inductance plethysmography with thoracoabdominal compression in bronchial challenges in infants and young children. Am J Respir Crit Care Med 1996;154:665-669.

19. Loland L, Buchvald F, Brydensholt Halkjaer L, Anhoj J, Hall G, Persson T, Krause TG, Bisgaard H. Sensitivity of bronchial responsiveness measurements in young infants. Chest 2006;129:669-675.

20. Hall G, Hantos Z, Wildhaber J, F P, Sly PD. Methacholine responsiveness in infants assessed with low frequency forced oscillation and forced expiration techniques. Thorax 2001;56:42-47.

21. Gutkowski P. Airway responsiveness following wheezy bronchitis in infants. Eur Resp J 1990;3:807-811.

22. O'Callaghan C, Milner AD, Webb MS, Swarbrick A. Nebulized water as a bronchoconstricting agent in infancy. Arch Dis Child 1991;66:948-951.

23. Yuksel B, Greenough A. Nebulized sodium cromoglycate in preterm infants protection against water challenge-induced bronchoconstriction. Respir Med 1993;87:37-42. 
24. Lum S, Hulskamp G, Hoo A-F, Ljungberg H, Stocks J. Effect of raised lung volume technique on subsequent measures of VmaxFRC in infants. Pediatr Pulmonol 2004;38:146-154.

25. Klug B, Bisgaard H. Measurement of lung function in awake 2-4-year old asthmatic children during methacholine challenge and acute asthma. Pediatr Pulmonol 1996;21:290-300.

26. Klug B, Bisgaard H. Measurement of the specific airway resistance by plethysmography in young children accompanied by an adult. Eur Respir J 1997;10:1599-1605.

27. Lanteri CJ, Raven JM, Sly PD. Effect of expiration on thoracic gas volume in wheezy infants. Pediatr Pulmonol 1990;9:220-223.

28. Delacourt C, Benoist MR, Waernessyckle S, Rufin P, Brouard JJ, de Blic J, Scheinmann P. Repeatability of lung function tests during methacholine challenge in wheezy infants. Thorax 1998;53:933-938.

29. Cartier A, Malo J-C, Begin P, Sestier M, Martin RR. Time course of the bronchoconstriction induced by inhaled histamine and methacholine. J Appl Physiol 1983;54:821-826. 